\title{
Impact of goat population management strategies on goat meat production in Bangladesh
}

\author{
F. Yasmin, ${ }^{1}$ K.S. Huque ${ }^{2}$, S.A. Chowdhury ${ }^{2}$ and M.A.H. Miyan ${ }^{2}$ \\ ${ }^{1}$ Agriculture Research Council, Farmgate, Dhaka-1215, 2 Bangladesh Livestock Research Institute, \\ Savar, Dhaka -1341.
}

\begin{abstract}
To increase goat-meat production, this study has been aimed to evaluate goat-meat production potentiality using different management strategies of goat-population rather than goat-meat productivity management in Bangladesh. Simulation Matrix (SIMM) model was used under three scenarios of goat-population management strategies such as Scenario1(Base rate): 2 kids/year production with $30 \%$ kid mortality, Scenario 2: Production of 6 kids/year with 30\% kid mortality and Scenario 3: Production of 6 kids/year with $10 \%$ kid mortality to analyze their impact on goat-meat production in Bangladesh. Results showed on average only 270.09 thousand ton /year of goat-meat can produce at the existing rate ( 2 kids Production/year with $30 \%$ kid mortality). If it is possible to increase kid production up to 6 then can produce on average 23714.4 thousand ton/year of goat-meat. Further, it is possible to reduce the kid mortality rate up to $10 \%$, goat-meat is the highest 932430.0 thousand ton/year. Result indicated a great positive impact of goat-population management strategies on goat-meat production. Therefore, $10 \% \mathrm{kid}$ mortality rate with 6 kids/year production of goat-population management could be suitable management or best strategy for higher goat-meat production in Bangladesh.
\end{abstract}

(Key words: Goat meat-production, Goat-population management, SIMM model.)

\section{Introduction}

Goat farms are important component for goat-meat production in Bangladesh. Black Bengal Goat (BBG) is famous for its high birth rate, delicious \& low fat meat and super quality skin. It plays an important role by producing meat, milk and skin in the national economy of Bangladesh for alleviating poverty. Livestock share of GDP was Tk.2.41 million (BBS, 2013). Some attempts have made through ensuring appropriate housing, feeding, health management, marketing and breeding for productivity increase. The supply of balanced rations to animals, infrastructural development and adoption of modern conservation practices with adequate veterinary coverage, availability of inputs and credit are some of the measures to increase goat production across the country. Ershaduzzaman (2007) studied on the disease and mortality pattern of goats under farm conditions and some factor affecting mortality and survival rates in Black Bengal kids. Mortality rate of goat were found changed significantly with different farm categories (Sayeed, 2005). Overall adult mortality was 12.69. Higher (43.45\%) mortality was observed under farms and rural condition. Kid mortality reduced from 35\% at low level of feeding to $5.5 \%$ at high level of feed of dam during gestation (Chowdhury et al, 2002).

It is really a gigantic task requires comprehensive approach to develop the sector through genetic improvement of goat. In fact, slow growth rate of goat meat

*Corresponding author: f.yasmin@barc.gov.bd

Bang. J. Livs. Res. Special Vol. 21-25, 2018: P. 118-126, ISSN 1022-3851 
production is related to the number of goat-population. Lower number of total female breeding stock goat may be the main reason for lower number of total goat population. Higher rate of kid mortality and lower number of kid production are the reason of lower number of total goatpopulation. Consequently, the rates of kid production and kid mortality are the main effective inputs for increasing goat-meat production. If appropriate improved management strategies would be undertaken by increasing kid production rate and reducing kid mortality rate in Bangladesh, there would have a bright prospect for improving the conditions of the rural poor farmers and the national economy through goat-meat production. So, if problem factors can be removed there will be a possibility for higher level of goat-meat production. The only way left to promote the goat-meat industry is increasing female breeding stock of goat through improved management because this only can produce higher number of total goat-population and encourage in increase the goat-meat production in future. Therefore, there is a need to examine the appropriate kid production and kid mortality rate of goat-population and their impacts on the probability of goat-meat production for the future.

Goat-meat production can increase by applying management strategies of rising productivity and rising number of goatpopulation under stall feeding, semiintensive and intensive farming. A number of researches have done meat productivity management. A very few research on goatpopulation has done. Yasmin, et al. (2000) reported that if increased yearly 30 thousand importation of beef cattle female breeding stock at $15 \%$ slaughter rate can increase beef production up to more than $30 \%$ by the year 2015. The impact of 30 thousand imported female breeding stock at $10 \%$ slaughter rate can increase the beef production up to more than $40 \%$ by the year 2015 in Malaysia. Yasmin et al. (2001) studied among different management strategies such as, yearly 25 thousand heads of each beef cattle, dairy cattle and buffalo female breeding stock importation with higher calving rate (70-80\%), Slaughter rate (15-20\%) and lower mortality rate (1-2\%); would be the best strategy for the highest beef production and $100 \%$ achievement of beef self-sufficiency in Malaysia.

In case of Bangladesh, government has taken initiatives to increase goat-meat production for poverty alleviation. In order to alleviate poverty, Bangladesh needs to increase her goat-meat production through higher total goat population in future. Since there are dynamic changes in the goat sub-sector, the simulation approach at different rates may provide valuable policy measures of goat-meat production in near future for poverty alleviation. In 2004, Yasmin studied about that the mutton production for future Bangladesh. But no study has been done on management strategy of goat-population. In Bangladesh, goat-population managements for different rates of kid production and mortality requires SIMM model to examine their impact on goat-meat production. On the above background, the present study was undertaken to evaluate the impact of different goat-population management strategies on goat-meat production in Bangladesh. 


\section{Materials and Methods}

\section{Theoretical Framework}

\section{System Simulation}

For the model system simulation, a system can be defined as a collection of components and their interrelationships which have been grouped together for the purpose of studying some part of the real world. In this study system approach includes such ideas as those of the system philosophy and the way of thinking about solving production problem in terms of a system simulation. System analysis is a technique used in analyzing the system and, the system approach itself is the style of managing the system. Subjective assessment explains simple graphical display of model-output in relation to the controllable and uncontrollable exogenous variables and possible relative to real-system output.

The general system may be represented in a schematic fashion as in Figure 1.

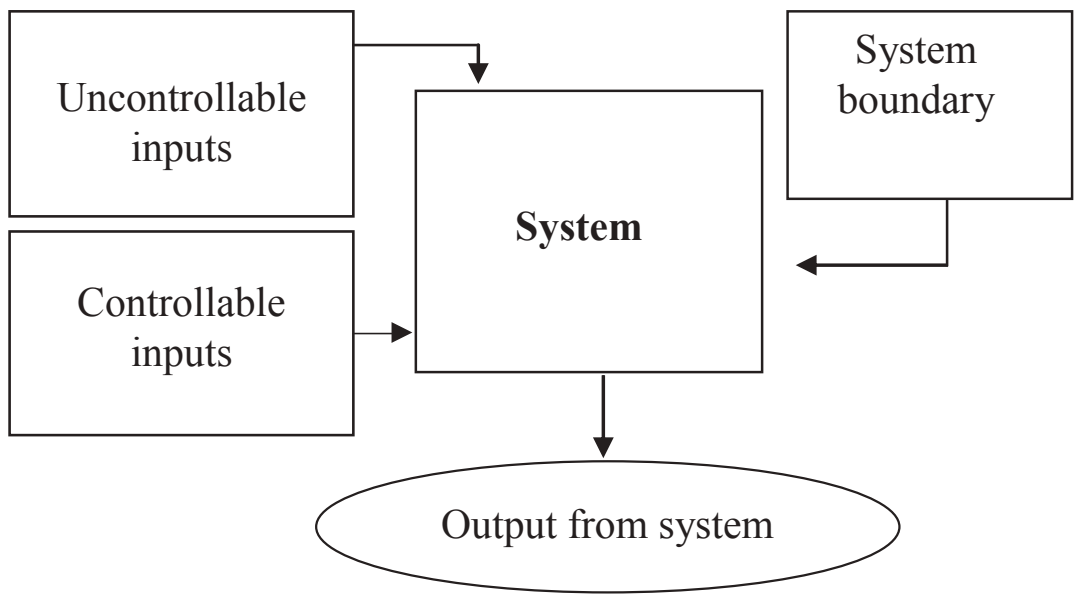

Figure 1: The Concept of a System

changes in the value of the level while the auxiliary represents factor may influence rates. The goat production from the system is dependent on the stream of kidding rate and mortality rate imposed upon the system. Simulation is a procedure simulation of equations for computing successive time increments. In doing so this process traces a time path representing the dynamics of the system.

An ex-post model validation test is used in order to determine whether the model is a valid mimicry of the real system simulated. The structural and behavioral relationships in the model are theoretically accepted, internally corrected and made consistent in a logical and programming sense. The procedure involved a series of computer runs with different variables. This analysis is similar to the analysis of the real world data, but there are some differences because randomness enters in a very complicated form in simulation experiment (ex-ante simulation). Several strategies have been tested in order to determine the effects of those strategies on production, to implement production policies (Yasmin, 2001).

The change of kid production and mortality rate in a real goat production system would change an output of goat-meat, than the

The level is a major component of a system whose changing values are particularly concerned. The rate directly brings about same direction of change should happen in the output-model. 


\section{Analytical Framework}

\section{Simulation Matrix (SIMM) Model}

The models for the estimating goat-population are considered using Livestock System Modeling: Simulation Matrix (SIMM) model; a Technology of Policy Analysis developed by Yasmin (2001) as follows:

\section{Goat-population Model}

\section{A. Female Goat}

Model for Female Goat:

$\mathrm{FG}_{(\mathrm{t}+\mathrm{DT})}=\int_{\mathrm{t}}^{\mathrm{t}+\mathrm{DT}}\left[\mathrm{FG}_{\mathrm{t}}-\mathrm{SFG}_{\mathrm{t}}-\mathrm{MFG}_{\mathrm{t}}\right] \mathrm{dt} \ldots \ldots$

Where,

$\mathrm{DT}=$ Increment of time

$\mathrm{FG}(\mathrm{t}+\mathrm{DT})=$ Current number of female goat for each age

$\mathrm{FG}_{\mathrm{t}}=$ Previous number of female goat for each age

SFGt $=$ Previous number of slaughtered female goat for each age

$\mathrm{MFG}_{\mathrm{t}}=$ Previous number of death female goat for each age

a) $\mathrm{SFG}_{\mathrm{t}}=\mathrm{A}_{1} * \mathrm{FG}_{\mathrm{t}} \ldots$

Where,

$\mathrm{A}_{1}=$ Slaughter rate for each age

The total number of slaughtered female goat generated by multiplying previous number of female goat at annual slaughter rate $\left(\mathrm{A}_{1}\right)$.

b) $\mathrm{MFG}_{\mathrm{t}}=\mathrm{A}_{2} * \mathrm{FG}_{\mathrm{t}}$

Where, $\mathrm{A}_{2}=$ Mortality rate

The total number of died female goat are generated by multiplying previous number of female goat at annual mortality rate $\left(\mathrm{A}_{2}\right)$.

\section{Model for Total Female Goat}

The grand total number of female goat is the sum of female goat for the current year.

$$
\mathrm{TFG}_{(\mathrm{t}+\mathrm{DT})}=\sum_{\mathrm{i}=1}^{\mathrm{n}} \mathrm{FG}_{\mathrm{i}(\mathrm{t}+\mathrm{DT})}
$$

Where,

$\mathrm{i}=2,3, \ldots \ldots \ldots, \mathrm{n}$ (years)

TFG $(\mathrm{t}+\mathrm{DT})=$ Total female goat of different ages in a current year

\section{Model for Female Kid}

$$
\mathrm{FK}_{(\mathrm{t}+\mathrm{DT})}=\mathrm{NFK}+\int_{\mathrm{t}}^{\mathrm{t}+\mathrm{DT}}\left[\mathrm{FK}_{\mathrm{t}}-\mathrm{MFK}_{\mathrm{t}}\right] \mathrm{dt} . \text {... }(3)
$$

Where,

$\mathrm{DT}=$ Increment of time

NFK $=$ Current new born female kids

$\mathrm{FK}_{(\mathrm{t}+\mathrm{DT})}=$ Current number of female kids for each age

$\mathrm{FKt}=$ Previous number of female calves for each age

MFKt $=$ Previous number of death female kids for each age

a) $\mathrm{MFK}_{\mathrm{t}}=\mathrm{C}_{2} * \mathrm{FK}_{\mathrm{t}}$.

Where,

$\mathrm{C}_{2}=$ Mortality rate

The total number of death female kids are generated by multiplying previous number of female calves at annual mortality rate $\left(\mathrm{C}_{2}\right)$.

\section{Model for Total Female Kid}

The total number of female kids is the sum female kids for the current year. 
$\mathrm{n}$

$\mathrm{TMK}_{(\mathrm{t}+\mathrm{DT})}=\Sigma \mathrm{MK}_{\mathrm{i}}$

$(\mathrm{t}+\mathrm{DT}) \ldots \ldots \ldots \ldots \ldots \ldots \ldots \ldots \ldots$

Where,

$$
i=1
$$

$\mathrm{i}=1,2 \ldots . ., \mathrm{n}$ (months)

TFK $(\mathrm{t}+\mathrm{DT})=$ Total female kids of different ages in a current year

\section{B. Male Goat}

The Model for Male Goat

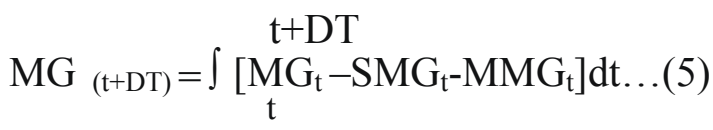

Where,

$\mathrm{DT}=$ Increment of time

MG $(t+D T)=$ Current number of male goat for each age

MGt $=$ Previous number of male goat for each age

SMGt $=$ Previous number of slaughtered male goat for each age

MMGt $=$ Previous number of death male goat for each age

a) $\mathrm{SMGt}=\mathrm{A}_{1} * \mathrm{MGt}$

Where,

$\mathrm{A}_{1}=$ Slaughter rate for each age

The total number of slaughtered male goat generated by multiplying previous number of male goat at annual slaughter rate $\left(\mathrm{A}_{1}\right)$.

b) $\mathrm{MMGt}=\mathrm{A}_{2} * \mathrm{MG}$

Where,

$\mathrm{A}_{2}=$ Mortality rate

The total number of died male goat are generated by multiplying previous number of male goat at annual mortality rate $\left(A_{2}\right)$.

\section{The Model for Total Male Goat}

The grand total number of male goat is the sum of male goat for the current year.

$$
\mathrm{TMG}_{(\mathrm{t}+\mathrm{DT})}=\underset{\mathrm{i}=1}{\sum \mathrm{MGi}_{\mathrm{i}(\mathrm{t}+\mathrm{DT})}}
$$

Where,

$$
\mathrm{i}=2,3, \ldots \ldots ., \mathrm{n} \text { (years) }
$$

TMG $(\mathrm{t}+\mathrm{DT})=$ Total male goat of different ages in a current year

\section{The Model for Male Kid}

$\mathrm{MK}_{(\mathrm{t}+\mathrm{DT})}=\mathrm{NMK}+\int_{\mathrm{t}}^{\mathrm{t}+\mathrm{DT}}\left[\mathrm{MK}_{\mathrm{t}}-\mathrm{MMK}_{\mathrm{t}}\right]_{\mathrm{dt}} \ldots(7)$

Where,

$\mathrm{DT}=$ Increment of time

NMK $=$ Current new born male kids

MK $(\mathrm{t}+\mathrm{DT})=$ Current number of male kids for each age

MKt $=$ Previous number of male kids for each age

MMKt $=$ Previous number of death male kids for each age

The following equations define the structure of the system:

a) $\mathrm{MMK}_{\mathrm{t}}=\mathrm{C}_{2} * \mathrm{MK}_{\mathrm{t}}$

Where,

$\mathrm{C}_{2}=$ Mortality rate

The total number of died male kids are generated by multiplying previous number of male kidss at annual mortality rate $\left(\mathrm{C}_{2}\right)$. 


\section{The Model for Total Male Kid}

The equation: The total number of male kids is the sum of male kids for the current year.

$$
\mathrm{TMK}_{(\mathrm{t}+\mathrm{DT})}=\sum_{\mathrm{i}=1}^{\mathrm{n}} \mathrm{MK}_{\mathrm{i}(\mathrm{t}+\mathrm{DT})}
$$

Where,

$\mathrm{i}=1,2 \ldots ., \mathrm{n}$ (months)

TMK $(\mathrm{t}+\mathrm{DT})=$ Total male kids of different ages in a current year

\section{Empirical Framework}

\section{Data collection and design}

Actual data on goat-population and meatproduction from the year 1985 to 2001 were collected from various issues of Bangladesh Bureau of Statistics (BBS).

\section{Data adjustment}

Female goat, male goat, female kid and male kid data were categorized using 35, 20, 23 and 22\% rate respectively (Honhold, 2001).

\section{Estimation Procedure}

Simulation Matrix (SIMM) model was used from 1985 to 2015 for goat in Bangladesh based on System Approach Method.

\section{Ex-post SIMM model}

System approach has been formulated and validated for the year 1985 to 2001 under an ex-post SIMM before performing an ex-ante SIMM experiment for the year 2002 to 2015.

\section{Ex-ante SIMM model}

After that an ex-ante SIMM estimation has been used to allow IF and THEN statement under different scenarios of goat-population and goat-meat production. The ex-post SIMM model for goat production system from 1985-2001 was used as a base to simulate the ex-ante component by changing the rates of kid production and kid mortality for the year 2002 to 2015 .

\section{Goat-population Management Strategies}

\section{Kid Production}

From different studies it is clear that kid production varies from 2 to 4 kids/year. Zeshmaran, 2007 mentioned BBG give birth twice a year or more commonly thrice in 2 years. Benefit of raising BBG mainly because of diseases are relatively less than other domestic animal and female goat become pregnant twice a year and give birth 2-3 baby goat each time (www.rayfarms.com/ blackbengalgoat). BBG is very popular in Bangladesh because of its very low demand of food and very high baby production rate. The BBG gain sexual maturity very fast. The female goat becomes pregnant twice a year gives birth to 3-4 baby goat every time (www.wikipedia.org/wikiblackbengalgoat).

\section{Mortality Rate}

From different studies it is clear that kid mortality almost $30 \%$. House-hold Survey of Animal Health Research Division of BLRI showed a kid mortality (0-6 months) of 29.9\% which were similar those for village goats in Nepal and Zimbabwe (Honhold, 2001) Growing goat mortality was $22.1 \%$ and about 30\% kid mortality was observed by Chowdhury et al. (2002) under semiintensive conditions. That is why existing kid mortality has considered as $30 \%$.

On these backgrounds for analyzing the impact of goat-population management 
strategies on production of goat-meat under 3 scenarios have taken as follows:

\section{Scenarios}

For every scenario, slaughter rate of castrated goat is $100 \%$ and culling rate of female goat is $100 \%$.

\section{Scenario 1: (Base rate): Production of 2 kids/ year with $30 \%$ kid mortality}

The lowest number of kid production (2 kids/year) and the highest kid mortality rate $30 \%$ considered under Scenario 1.

\section{Scenario 2: Production of 6 kids/year with $30 \%$ kid mortality}

Increasing kid Production from 2kids/year to 6 kids/year with remaining 30\% kid mortality considered under Scenario 2.
Scenario 3: Production of 6 kids/year with $10 \%$ kid mortality

Decreasing kid mortality rate from $30 \%$ to $10 \%$ with remaining kid Production 6kids/year considered under Scenario 3.

\section{Results and Discussion}

\section{Impact of goat-population management strategies under different scenarios}

\section{Goat-population management strategies under different scenarios}

Appropriate management system can successfully increase the number of goat in Bangladesh. Table 1 shows that only at 6 kids per year and $30 \%$ kid mortality, goat-

Table 1. Estimation of goat-population (Million heads) under goat-population management scenarios in Bangladesh

\begin{tabular}{|c|c|c|c|}
\hline Year & $\begin{array}{c}\text { Scenario 1 } \\
\text { (Base rate })\end{array}$ & Scenario 2 & Scenario 3 \\
\hline 2002 & 47.0 & 87.1 & 75.6 \\
\hline 2003 & 50.7 & 131.8 & 138.5 \\
\hline 2004 & 54.6 & 221.3 & 319.1 \\
\hline 2005 & 58.7 & 361.4 & 565.3 \\
\hline 2006 & 63.3 & 593.1 & 1039.1 \\
\hline 2007 & 68.1 & 970.3 & 1871.8 \\
\hline 2008 & 73.4 & 1593.1 & 3410.6 \\
\hline 2009 & 79.0 & 2610.5 & 6175.0 \\
\hline 2010 & 85.1 & 4282.0 & 11218.9 \\
\hline 2011 & 91.6 & 7020.1 & 20344.3 \\
\hline 2012 & 98.6 & 11512.1 & 36930.2 \\
\hline 2013 & 106.2 & 18875.9 & 67000.6 \\
\hline 2014 & 114.4 & 30952.1 & 121592.5 \\
\hline 2015 & 123.2 & 50752.6 & 220629.7 \\
\hline Av. & $\mathbf{7 9 . 6}$ & $\mathbf{9 2 8 3 . 1}$ & $\mathbf{3 5 0 9 3 . 7}$ \\
\hline
\end{tabular}

Note:

Scenario 1(Base rate): 2 kids/year with 30\% kid mortality (Yasmin, 2004)

Scenario 2: 6 kids/year with 30\% kid mortality

Scenario 3: 6 kids/year with 10\% kid mortality 
population increased from 87.1 million heads in 2002 to 50752.60 million heads in 2015 under scenario 2 whereas at $10 \%$ kid mortality rate, goat-population is 75.60 in 2002 to 220629.7 million heads in 2015 under scenario 3. From 2002 it increased rapidly under scenario 3 compared to scenarios 2 (Table 1). At the base/existing rates (2 kids per year with $30 \%$ kid mortality), goat-population is the lowest. Scenario 1, 2 and 3 show that goat-population increased from 47.00, 87.10 and 75.60 in 2002 to $85.10,50752.60$ and 220629.70 million heads in 2015 and on an average 79.6, 93283.10 and 35093.70 million heads respectively. Therefore, changing kid production and kid mortality can increase the number of goat-population.

It is true that increasing goat-population can increase the production of goat-meat in future. The effects of changing the number of goat-population on goat-meat production are shown in Table 2. Scenario 1, 2 and 3 show that goat-meat increased from 161.5, 171.5 and 175.8 in 2002 to $419.1,129667.4$ and 524862.1 thousand tons in 2015 and on an average 270.9, 23714.4 and 93,243 thousand tons respectively. Goat-meat production shows an increasing trend due to increasing number of goat-population (Table 1). Under different management strategies, scenario 2 shows the higher amount of goat-meat production. It is less compared to scenarios 3 . Scenarios 2 and 3 show that goat-meat production increased rapidly up to 2015 due to higher kid production and for lower kid mortality. The simulated results illustrate that the highest and higher amount of goat-meat production in the year (2015) is possible only under scenario 3 and scenario 2 compared to

Table 2. Estimation of goat-meat production (Thousand MT) under goat-population management scenarios in Bangladesh

\begin{tabular}{|c|c|c|c|}
\hline Year & Scenario 1 (Base rate ) & Scenario 2 & Scenario 3 \\
\hline 2002 & 161.5 & 171.5 & 175.8 \\
\hline 2003 & 171.4 & 391.7 & 199.5 \\
\hline 2004 & 186.6 & 518.3 & 667.1 \\
\hline 2005 & 199.6 & 952.6 & 1432.4 \\
\hline 2006 & 215.5 & 1486.4 & 6387.4 \\
\hline 2007 & 231.9 & 2502.6 & 4534.7 \\
\hline 2008 & 249.7 & 4050.4 & 8030.7 \\
\hline 2009 & 268.9 & 6686.2 & 147687 \\
\hline 2010 & 289.5 & 10925.3 & 26604.9 \\
\hline 2011 & 311.8 & 17946.6 & 48469.8 \\
\hline 2012 & 335.7 & 29401.0 & 87763.7 \\
\hline 2013 & 361.5 & 48231.9 & 159443.7 \\
\hline 2014 & 389.2 & 79069.1 & 289142.6 \\
\hline 2015 & 419.1 & 129667.4 & 524862.1 \\
\hline Av. & $\mathbf{2 7 0 . 9}$ & $\mathbf{2 3 7 1 4 . 4}$ & $\mathbf{9 3 2 4 3 . 0}$ \\
\hline
\end{tabular}

Note:

Scenario 1(Base rate): Production of 2 kids/year with 30\% kid mortality (Yasmin, 2004)

Scenario 2: 6 kids/year with 30\% kid mortality

Scenario 3: 6 kids/year with 10\% kid mortality 
scenario 1 (base rate) respectively.

The results cast that the lowest kid mortality rate with the highest kid production per year of goat-population has a great impact on the goat-meat production.

\section{Conclusion}

Not only in small amount but slowly the production of goat-meat can be increased by increasing productivity using special feeding, housing and care which is not the actual solution of meet-up goat-meat demand in the context of Bangladesh. The results of SIMM technology indicated only higher number of total female goat maintain higher number of goat-population, so in order to increase goatmeat, the rates of mortality will have to be reduced from $30 \%$ to $10 \%$ and the number of kid production needs to increase from 2 kids to $6 \mathrm{kids} /$ year. In order to reach the targets efforts need special care for reducing kid mortality and breed development for higher kid production. Therefore, to increase total goat-population government should create; vaccination, heath and medical care facilities for reducing kid mortality rate and opportunities to produce/supply high breed goat for higher kid production.

\section{References}

BBS. 2005. Statistical Year Book of Bangladesh. Bangladesh Bureau of Statistics, Government of the People's Republic of Bangladesh, Dhaka.

BBS. 2013. Statistical Pocket Book of Bangladesh. Bangladesh Bureau of Statistics, Government of the People's Republic of Bangladesh, Dhaka. p.280-300

Chowdhury, S.A., Bhuiyan, M.S.A. and Faruk, S. 2002. Rearing Black Bengal Goat under semi-intensive management. 1. Physiological and Reproductive Performance. AsianAustralasian Journal of Animal Science, 15 (4) :447-484.

Ershaduzzaman, M., Rahman, M., Roy, B.K. and Chowdhury, S.A. 2007. Studies on the Diseases and Mortality Pattern of Goats under Farm Conditions and Some Factor Affecting Mortality and Survival Rates in Black Bengal Kids, Bangladesh Journal of Veterinary Medicine, 5 (1 \& 2):71-76.

Honhold, N. 2001. Veterinary epidemiologist. ARMP Project, November 12-April 24, BLRI, Dhaka.

Internet: www. roy farms.com/black bengal goat

Internet:www.wikipedia.org./wikiblack_bengal_ goat

Sayeed, M.A., Rahman, S.M.A., Taimur, M.J.F.A., Faruk, S. and Yasmin, F. 2005. Effect of Farm Categories on Prevalence of Goat Diseases and Financial Loss under Scavenging System of Rearing in Some Selected Areas of Bangladesh, Bangladesh Journal of Livestock Research. Vol. 12 (1 \& 2):58-65

Yasmin, F., Zainalabidin, M., Mad Nasir, S., and Eusof, A.J.M. 2000. Policy Analysis of Beef Production in Peninsular Malaysia. Proceedings of the 12th Veterinary Association Malaysia Scientific Congress, Kuantan, Pahan, Malaysia.1-4, September 2000: 61-62.

Yasmin, F., Zainalabidin, M., Mad Nasir, S., and Eusof, A.J.M. 2001. Policy Analysis of Beef Production System in Peninsular Malaysia. Unpublished Ph.D Thesis. University Putra Malaysia, Malaysia.

Yasmin, F., Haque, K.S., Chowdhury, S.A. and Miyan, M.A.H. 2004. Estimation of Future Mutton Production in Bangladesh. Bangladesh Journal of Livestock Research.10 (1 \& 2): 27-31.

Zeshmarani, S., Dhara, K.C., Samanta, A.K., Samanta, A.R. and Majumder, S.C. 2007. Reproductive Performance of Goats in Eastern and Northern India. Livestock Res. Rural Dev. 19.8 